\title{
Sharing the blame: smoking experimentation and future smoking-attributable mortality due to Joe Camel and Marlboro advertising and promotions
}

\author{
John P Pierce, Elizabeth A Gilpin, Won S Choi
}

\begin{abstract}
Background-Despite public denials, internal tobacco company documents indicate that adolescents have long been the target of cigarette advertising and promotional activities. Recent longitudinal evidence suggests that $34 \%$ of new experimentation occurs because of advertising and promotions.

Objective-To apportion responsibility for smoking experimentation and future smoking-attributable mortality among major cigarette brands attractive to young people (Camel and Marlboro).

Data sources, setting, and participantsData were from confirmed never-smoking adolescents (12-17 years old) responding to the $1993(n=2659)$ and $1996(n=2779)$ population-based California Tobacco Surveys.
\end{abstract}

Main outcomes-Adolescents named the brand of their favourite cigarette advertisements and tobacco promotional items. Using these "market shares" and the relative importance of advertising and promotions in encouraging smoking, we estimated how many new experimenters from 1988 to 1998 in the United States can be attributed to Camel and Marlboro. From other data on the natural history of smoking, we projected how many future deaths in the United States can be attributed to each brand.

Results-Although Camel advertisements were favoured more than Marlboro and other brands in 1993 and 1996, the "market share" for promotional items shifted markedly during this period from Camel and other brands towards Marlboro. We estimated that between 1988 and 1998, there will be 7.9 million new experimenters because of tobacco advertising and promotions. This will result in 4.7 million new established smokers: 2.1, 1.2, and 1.4 million due to Camel, Marlboro, and other brands' advertising and promotions, respectively. Of these, 1.2 million will eventually die from smokingattributable diseases: 520000 from Camel, 300000 from Marlboro, and the remainder from other brands.

Conclusions-Our analysis provides a reasonable first estimate at sharing the blame for the long-term health consequences of smoking among the major brands that encourage adolescents to start smoking. (Tobacco Control 1999;8:37-44)

Keywords: adolescence, smoking initiation, smoking-attributable diseases, advertising

\section{Introduction}

"Realistically, if our Company is to survive and prosper over the long term, we must get our share of the youth market. In my opinion, this will require new brands tailored to the youth market.... Several things will go to make up such new 'youth' brands, the most important of which may be the image and quality ... What image? and What quality? Perhaps these questions may best be approached by consideration of factors influencing pre-smokers to try smoking, learn to smoke and become confirmed smokers."

Rf Reynolds Confidential Research Planning Memorandum, $\mathrm{Feb} 2,1973 .{ }^{1}$

Many studies have demonstrated that adolescents are attracted to tobacco industry advertising and promotions. ${ }^{2} 3$ Brands smoked by adolescents are the brands most advertised, ${ }^{4-7}$ and advertisements for these brands are more likely to appear in magazines with a significant adolescent readership. ${ }^{8}$ A sharp increase in initiation of smoking by adolescent girls was observed coincident with advertising campaigns launching new women's brands of cigarettes, ${ }^{9}$ and a similar increase in adolescent smoking occurred for earlier innovative cigarette advertising campaigns. ${ }^{10}$ Receptivity to cigarette advertising and promotions was positively related to which never-smoking adolescents were susceptible to smoking. ${ }^{11} \quad$ A recent longitudinal study confirmed that non-susceptible never-smokers are more likely to progress toward smoking if they are receptive to tobacco advertising and promotions. ${ }^{12}$ This analysis adjusted for demographics, school performance, and exposure to smokers among peers or the family. The receptivity effect was present regardless of what other known predictors of smoking uptake were included in the analysis.

There are five criteria for assessing the causality of an agent in epidemiological studies, ${ }^{13}$ and based on these criteria, tobacco advertising and promotions can be considered a causal agent for smoking uptake. ${ }^{12}$ Receptivity to tobacco advertising and promotions temporally precedes the adolescent taking the first identifiable step towards becoming a smoker, the association is strong, specific, and consistent with results from the other studies mentioned above, and it is what would be expected from how persuasive communications work. ${ }^{12} 14$ 
The public health problem with adolescent cigarette experimentation is that a substantial proportion of experimenters will go on to become addicted to cigarettes, ${ }^{215-17}$ and many of those who become addicted will die of a smoking-attributable disease ${ }^{18-20}$ a substantial proportion after a lifelong unsuccessful struggle to overcome their addiction. This has led to a number of lawsuits seeking redress from the tobacco industry, including individual claims, class actions, and lawsuits on behalf of states, major insurance companies, and labour union pension plans. $^{21}$ Since King et al clearly indicated that not all advertising and promotion of cigarettes is equally placed to attract adolescent audiences, ${ }^{8}$ and other studies show that not all brands' advertising and promotions are equally attractive to young people, ${ }^{45}$ it is meaningful to partition the influence on adolescent smoking by cigarette brand.

In our previous study, ${ }^{12}$ two categories of receptivity to cigarette advertising and promotion were strongly predictive of which adolescents (12-17 years of age) who were confirmed never-smokers would progress toward smoking. One of these categories was the nomination of the brand of a favourite cigarette advertisement and the other included possession (brand identified) or willingness to use a tobacco promotional item. The analysis suggested that the promotional item category was about $50 \%$ more influential than the advertising category. A third item, which just failed to reach statistical significance in this analysis, was the brand that might be bought if the never-smoker wanted to buy a pack. This additional information on brand awareness was related to awareness of advertising for that brand and it could be argued that this brand information is equivalent to the brand of the favourite advertisement.

In this article, we use the receptivity information about the cigarette brands named in two large, representative cross-sectional surveys of the California adolescent population to develop an estimate of the proportionate responsibility major brands have in encouraging adolescents to experiment with smoking. Assuming that the influence of cigarette advertising and promotions in California during this period is not very different from the influence in the rest of the United States, we estimate the overall number of new American experimenters that can be attributed to each brand. Since both the public health and the legal systems are concerned about smoking-attributable deaths, we also provide an estimate for the number of future deaths that might be attributed to each brand in the United States. First of all, we do this using the index of receptivity that was demonstrated to predict progress towards smoking. Then we repeat the analysis using the brand that the adolescent might buy as equivalent to the nominated favourite advertisement.

\section{Methods}

DATA SOURCES

Random-digit-dialed telephone surveys, the California Tobacco Surveys (CTS), are conducted periodically to evaluate the Califor- nia Tobacco Control Program..$^{22}$ The 1993 and 1996 CTS drew a clustered random sample designed to be representative of the California population. $^{24}{ }^{25}$ An adult in each household enumerated all household members, and interviewers obtained verbal parental permission to interview all adolescents $12-17$ years of age. A 20-minute interview was conducted with these teenagers, which covered topics including smoking behaviour, knowledge and attitudes about smoking, and about tobacco advertising and promotions. The household level response rates, which assume that a certain percentage of telephone numbers never reached are households, were $70.0 \%(n=32135)$ in 1993 and $55.3 \%(n=39674)$ in 1996. In 1993, the adolescent extended interview had a response rate of $80.3 \%(n=5040)$ and the 1996 adolescent survey had a response rate of $71.2 \%(\mathrm{n}=$ 6252). Sample weights were computed to reflect the probability that an individual was interviewed. Next, the weights were ratio adjusted to population census totals to ensure that estimates derived from the sample are representative of the California population by sex, age, race/ethnicity, and the educational attainment of the adult head of household. ${ }^{23} 24$

\section{SURVEY QUESTIONS}

Identification of confirmed never-smokers

As in the previous research, ${ }^{12}$ we only consider adolescents who have never smoked and who have strong intentions not to smoke. A never-smoker was someone who answered 'no' to the following questions: "Have you ever smoked a cigarette?" and "Have you ever tried or experimented with cigarette smoking, even a few puffs?" Three questions are used to distinguish confirmed or non-susceptible neversmokers: (a) "Do you think that you will try a cigarette soon?"; (b) "If one of your best friends were to offer you a cigarette, would you smoke it?"; and (c) "At any time during the next year do you think you will smoke a cigarette?" Confirmed or non-susceptible never-smokers had to answer 'no' in 1993 and 'definitely not' or 'probably not' in 1991 to the first question, and 'definitely not' to the second two. There were 2659 confirmed neversmokers analysed for 1993 and 2779 for 1996.

\section{Receptivity to tobacco advertising/promotions market share}

In the 1993 and 1996 CTS, there were questions to characterise the level of receptivity of adolescents to tobacco advertising and promotions. ${ }^{11}{ }^{12}$ All adolescents were asked questions about promotional items: "Some tobacco companies provide promotional items to the public that you can buy or receive for free. Have you ever brought or received for free any product which promotes a tobacco brand or was distributed by a tobacco company?" For respondents who indicated that they had, several questions about the item were asked, including: "What tobacco brand provided the most recent item that you bought or received for free?" Adolescents who did not have a tobacco promotional item were asked: "Do you think you would ever use a tobacco industry 
promotional item such as a T-shirt?" Respondents who either had a promotional item or who were willing to use an item were classified as highly receptive. Confirmed never-smokers in this highly receptive group were nearly three times as likely to have increased their probability of future smoking over a three-year period as those who were minimally receptive. ${ }^{12}$

For adolescents not in this highly receptive group, moderate receptivity to advertising was established with the question: "What is the name of the cigarette brand of your favourite advertisement?" For the few adolescents who hesitated in their response, we probed with the question: "Of all the cigarette advertisements you have seen, which do you think attracts your attention the most?" Confirmed adolescent never-smokers who could name a brand in response to these questions are considered moderately receptive, and they had nearly twice the risk of increasing their likelihood of future smoking as the minimally receptive group. $^{12}$

A respondent who could not name any brand of advertising or who objected to all cigarette advertising in response to the question: "Think back to the cigarette advertisements you have recently seen on billboards or in magazines. What brand of cigarettes was advertised the most?" was categorised as minimally receptive. All others were classified as having a low level of receptivity. Being classified as having a low level of receptivity did not significantly increase the likelihood of future smoking. ${ }^{12}$ For the purposes of the present article, we designated the low and minimally receptive groups as non-receptive and the other two groups described in the preceding paragraphs as receptive to tobacco advertising and promotions in the year considered.

\section{APPORTIONING RESPONSIBILITY BY BRAND}

From the brand names provided as responses for promotional items owned or named as the favourite advertisements, a "market share" for different brands can be determined. The brand "market share" for promotional items will be based on confirmed never-smokers who have them, and it will be assumed that the distribution for those who do not have an item but who would be willing to use one would be the same.

Let the "market share" for brand $b$ for promotions be designated as $\mathrm{ms}(\mathrm{p})_{b}$ and the "market share" for brand $b$ for advertising be designated as $\mathrm{ms}(\mathrm{a})_{b}$. We will assume that advertising accounts for a proportion, e(a), of the marketing effect and that promotional items account for $1-e(a)$. The parameter $e(a)$ reflects both the relative prevalence and the relative influence on future smoking of receptivity to advertising. A discussion of reasonable values for this parameter is presented below. The total promotions and advertising effect, $\mathbf{R}_{b}$, for brand $b$ can be expressed as

$$
\mathrm{R}_{b}=\mathrm{e}(\mathrm{a}) \times \mathrm{ms}(\mathrm{a})_{b}+(1-\mathrm{e}(\mathrm{a})) \times \mathrm{ms}(\mathrm{p})_{b}
$$

The proportions, $\mathrm{ms}(\mathrm{a})_{b}$ and $\mathrm{ms}(\mathrm{p})_{b}$, will be estimated from the 1993 and 1996 CTS.
If brand "market share" for advertising or promotions differs over time, this will need to be taken into account by computing different values for $\mathrm{R}_{b}$ for different periods of interest.

We then repeated this analysis to take better account of the respondents who, in addition to having a favourite advertisement, also nominated a brand in response to the question, "If you wanted to buy a pack of cigarettes tomorrow, what brand do you think you would buy?" Of these respondents, approximately half named a different brand from the one that they nominated as their favourite advertisement. Provided that this different brand had also been nominated as a brand which they had seen advertised, we repeated the analysis treating this additional information as equal to the information from their favourite advertisement.

PROJECTING MORTALITY BY BRAND

Assuming that the relationship between receptivity to tobacco marketing and promotions is causal, our previous study indicated that $34.3 \%$ of all future experimentation by confirmed adolescent never-smokers can be attributed to tobacco advertising and promotions. ${ }^{12}$ We indicated above how brand "market share" and the relative importance of promotions and advertising can be used to apportion the responsibility for experimentation among cigarette brands. Various studies provide estimates for the number of new experimenters and the percentage of experimenters who become addicted smokers. ${ }^{215-1725}$ Data also exist on the typical duration of cigarette addiction in the United States ${ }^{26}$ and estimates of smoking-attributable mortality among long-term smokers. ${ }^{18-20}$

We will apply these estimates to compute an estimate of the projected number of future deaths resulting from all new experimentation for the 11-year period from 1988 through the year 1998. The year 1988 was the first full year of the RJ Reynold's Joe Camel campaign.

CHOICE OF ESTIMATES/PARAMETERS

Experimentation and addiction

The oft-quoted phrase " 3000 new teen smokers each day" is from an article that used a national survey of adults to estimate the number of 20-year-old current smokers in the population who had smoked at least 100 cigarettes in their lifetime. Assuming steady accrual throughout the year, this number was divided by 365 to obtain the daily rate. ${ }^{25}$ This figure is an estimate of the number of young people who become established smokers each day rather than the number who experiment for the first time.

A recent analysis of the 1994-1997 National Household Surveys on Drug Abuse estimated that in 1988, close to 5300 American adolescents $12-17$ years of age experimented with cigarettes for the first time each day. ${ }^{27}$ In 1995 , the estimate was close to $6600 /$ day. This study confirmed other recent work that indicated adolescent smoking has been increasing in the United States since the early 1990s. ${ }^{32-30}$ Because of the upturn in 
adolescent smoking, we will use these two period-specific estimates for the number of new experimenters per day in each period. This study also showed that over 3200 American adolescents progressed to daily smoking each day in 1995, and that nearly 3400 per day progressed in 1996. These figures suggest that the fraction of experimenters that progress to daily smokers while between the ages of 12 and 17 years is about $50 \%$. However, some adolescents progress to daily smoking after the age of 17 years, and they are not taken into account in the $50 \%$ figure.

There are other estimates for the number of experimenters who progress to become established smokers. An analysis of the longitudinal 1989-1993 Teenage Attitudes and Practices Survey (TAPS) data indicated that around $30 \%$ of adolescents who reported experimenting with cigarettes at baseline, but who had not yet smoked at least 100 cigarettes in their lifetime, had reached 100 cigarettes and were current smokers (smoked in the last 30 days) at follow up four years later. ${ }^{16} \mathrm{~A}$ nationwide study of high-school students found that $36 \%$ of those who had ever tried smoking became daily smokers. ${ }^{17}$ These estimates are probably very conservative. In the TAPS study, there were many respondents who reported no smoking ever at baseline, but who reported smoking at least 100 cigarettes and were current smokers at follow up. The school survey did not include high-school dropouts, who may have a much higher rate of progression to daily smoking, and some students may not become daily smokers until after they graduate. Finally, daily smoking is a higher level of addiction than a report of a lifetime consumption of at least 100 cigarettes and current smoking.

Surveys of adults indicate that about $70 \%$ of respondents who admitted smoking at least one cigarette also reported smoking at least 100 cigarettes in their lifetime. ${ }^{15} 31$ However, this may be an overestimate, as some adults who minimally experimented as young people may not even recall ever smoking at all. We will use $60 \%$ as the rate of progression for those who experiment to becoming established smokers. This allows for some progression to regular smoking after age 17, and yet is conservatively less than the estimate derived from adult surveys.

Duration of smoking and smoking-attributable mortality

A birth cohort analysis of American data projected that $50 \%$ of today's new smokers (those born between 1975 and 1979 and who smoked at least 100 cigarettes in their lifetime, which satisfies the definition of an ever-smoker) will smoke until their mid-30s before they successfully quit. $^{27}$ A 40-year follow-up study of male British physicians indicated that $50 \%$ of those who continued to smoke beyond their mid-30s died of smokingattributable diseases. ${ }^{19}$ An estimate from a longitudinal sample of American smokers (including males and females), with the final follow up in 1988, also established that about
$50 \%$ of deaths in current smokers age 35 and older can be attributed to their smoking. ${ }^{20}$ Multiplying the percentages of those who reach middle age as smokers and the expected smoking-attributable mortality suggests that $25 \%$ of ever-smokers will die of smokingattributable diseases. Another report used data from male American veterans studied in the late 1950 s and 1960 s to construct a first estimate of smoking-attributable mortality in the general population. These mortality rates were then scaled to the mortality rates for the American population in 1982 . This study estimated that as many as a third of heavy smokers ( $>25$ cigarettes/day) aged 35 years will die of a smoking-attributable disease before they reach the age of $85 .{ }^{18}$ Although this estimate is lower than those from the other studies, the other studies are more contemporaneous and have fewer methodological problems. Thus, we will use the estimate that $25 \%(50 \%$ of $50 \%$, rather than $33 \%$ of $50 \%$ ) of ever-smokers will die of a smoking-attributable disease.

The parameter, $e(a)$

As stated earlier, the parameter e(a) accounts for the relative effectiveness of advertising compared with promotions in encouraging future smoking and for the relative prevalence of receptivity to advertising compared with promotions among receptive adolescents. As will be seen later, having or being willing to use a promotional item accounts for only approximately $30 \%$ of the receptivity relative to favourite advertisements. Thus, the choice of $\mathrm{e}$ (a) depends on the relative importance of promotions and advertising in influencing experimentation. By making different assumptions about relative importance, we were able to perform a sensitivity analysis. The basis for these calculations and the results are presented in the appendix. Varying the relative importance (from being about equally important, to promotions being 1.5 times more important than advertising, to promotions being two times more important) only changed the value of $\mathrm{e}(\mathrm{a})$ over a range from 0.63 to 0.77 . Considering a slightly broader range (0.6-0.8) did not change the numbers of new experimenters attributable to each brand appreciably (see appendix).

\section{Results}

RECEPTIVITY TO TOBACCO ADVERTISING AND PROMOTIONS

Overall in 1993, $70 \%$ of confirmed never-smokers were categorised as receptive to tobacco advertising and promotions, and this declined slightly to $67 \%$ in 1996 , with the reduction accounted for by a decreasing percentage who named a favourite advertisement. Among receptive confirmed neversmokers, the type of receptivity (promotions or advertising) is described in table 1 . Overall, the percentage of those who own a promotional item increased, with the younger age groups showing increases and the oldest one showing a decrease. The percentage of those who have no item, but who would be willing to use one, showed a similar age-related pattern but to a 
Table 1 Type of receptivity among receptive, confirmed never-smokers from the 1993 and 1996 California Tobacco Surveys

\begin{tabular}{|c|c|c|c|c|c|c|}
\hline \multirow[b]{3}{*}{ Age (years) } & \multicolumn{4}{|c|}{ Highly receptive (\%) } & \multirow{2}{*}{\multicolumn{2}{|c|}{$\begin{array}{l}\text { Moderately receptive } \\
\text { Has favorite ad }(\%)\end{array}$}} \\
\hline & \multicolumn{2}{|c|}{ Have item } & \multicolumn{2}{|c|}{ No item, but would use } & & \\
\hline & 1993 & 1996 & 1993 & 1996 & 1993 & 1996 \\
\hline $12-13$ & 5.7 & 10.3 & 10.7 & 12.0 & 83.6 & 77.8 \\
\hline $14-15$ & 8.1 & 11.5 & 15.5 & 16.0 & 76.5 & 72.6 \\
\hline $16-17$ & 12.0 & 9.4 & 20.1 & 15.9 & 67.8 & 75.1 \\
\hline Overall & 8.1 & 10.3 & 14.7 & 14.3 & 77.2 & 75.1 \\
\hline
\end{tabular}

Only confirmed never-smokers receptive to promotions and advertising are considered in this table. The percentages in any row for a given year account for the type of receptivity among those receptive and thus add to $100 \%$.

Table 2 Market share of promotional items possessed by highly receptive*, confirmed never-smokers from the 1993 and 1996 California Tobacco Surveys

\begin{tabular}{lllllllll}
\hline & \multicolumn{2}{l}{ Camel (\%) } & & \multicolumn{2}{c}{ Marlboro (\%) } & & \multicolumn{2}{c}{ Other (\%) } \\
\cline { 2 - 3 } \cline { 8 - 9 } Age (years) & 1993 & 1996 & & 1993 & 1996 & & 1993 & 1996 \\
\hline $12-13$ & 40.0 & 19.2 & & 8.9 & 53.9 & & 51.1 & 26.9 \\
$14-15$ & 25.0 & 24.6 & & 22.9 & 47.8 & & 47.9 & 26.6 \\
$16-17$ & 25.9 & 17.8 & & 31.0 & 48.9 & & 43.1 & 33.3 \\
Overall & 29.8 & 20.9 & & 21.9 & 50.5 & & 48.3 & 28.6 \\
\hline
\end{tabular}

*Highly receptive adolescents either have a promotional item or would be willing to use one. It is assumed that the brand distribution for those who do not have an item but who would be willing to use one is the same as for those who have an item

Table 3 Market share of favourite advertisements of confirmed never-smokers who are moderately receptive* smokers from the 1993 and 1996 California Tobacco Surveys

\begin{tabular}{lllllllll}
\hline & \multicolumn{2}{c}{ Camel (\%) } & & \multicolumn{2}{c}{ Marlboro (\%) } & & \multicolumn{2}{c}{ Other (\%) } \\
\cline { 2 - 3 } Age (years) & 1993 & 1996 & & 1993 & 1996 & & 1993 & 1996 \\
\hline $12-13$ & 54.0 & 56.8 & & 16.5 & 17.2 & & 29.5 & 26.0 \\
$14-15$ & 47.5 & 52.3 & & 22.9 & 25.2 & & 29.6 & 22.5 \\
$16-17$ & 40.7 & 52.1 & & 25.4 & 24.6 & & 33.9 & 23.3 \\
Overall & 48.9 & 54.1 & & 20.5 & 21.7 & & 30.6 & 24.2
\end{tabular}

*Do not own and are not willing to use a promotional item, but did name the brand of their favorite cigarette advertisement.

lesser degree, so that the net change was minimal. In 1993, the percentage of receptive confirmed never-smokers with a favourite advertisement decreased with age, but this was no longer the case in 1996. In 1993, the overall relative prevalence of promotional item receptivity to favourite advertisement receptivity was

$$
\mathrm{r}(\mathrm{p}) / \mathrm{r}(\mathrm{a})=(8.1+14.7) / 77.2=0.295
$$

where $r(p)$ is receptivity to promotions and $r(a)$ is receptivity to advertising.

In 1996, the ratio was

$$
(10.3+14.3) / 75.1=0.328 \text {. }
$$

\section{MARKET SHARE}

\section{Promotional items}

Table 2 shows that there was a major shift in the "market share" of promotional items owned by adolescents for Camel and Marlboro between 1993 and 1996. Over all ages, Camel accounted for $29.8 \%$ of the items owned in 1993 but only $20.9 \%$ of items owned in 1996 , whereas Marlboro increased its share of items owned from $21.9 \%$ in 1993 to $50.5 \%$ in 1996 . Younger adolescents showed this shift to a greater degree than older ones.
Favourite advertisements

Among confirmed never-smokers who do not own or want to use promotional items and who had a favourite ad, the percentages of adolescents naming Camel and Marlboro as their favourite advertisement were relatively stable between 1993 and 1996 (table 3). However, Camel appeared to gain some "market share" or attractiveness to adolescents at the expense of brands other than Marlboro, and this was true for all age groups. All other brands are grouped together because no other brand accounted for more than 8\% (Virginia Slims was $7.2 \%$ in 1993) of the favourite advertisements in either year.

APPORTIONMENT OF EXPERIMENTATION

Interpreting previous work as establishing a causal relationship, one can compute that advertising and promotions were responsible for a total of 7.9 million new American experimenters from 1988 to 1998: 4.6 million from 1988 to 1994, and 3.3 million from 1995 to 1998 (table 4). The number of new experimenters for the period from 1988 to 1994 is from the calculation

$(5300 /$ day $) \times(365$ days/year $) \times 7$ years $\times 34.3 \%$.

The $34.3 \%$ is the previously published estimate of the percentage of new experimentation attributable to tobacco advertising and promotions. ${ }^{12}$ For the second period, 6600 per day and four years were used in the above calculation.

Using the formula presented in the Methods section for determining the proportion of new experimentation attributable to a given brand, produces the results shown in table 4 . These projections take into account the changes in "market share" for promotions and advertising between 1993 and 1996 observed from tables 2 and 3. From 1988 to 1998 , we estimate that the Joe Camel campaign will be responsible for 3.5 million new American experimenters, the Marlboro campaign for 2.0, and other brands for 2.5 million.

If $60 \%$ of new experimenters become established smokers (report smoking at least 100 cigarettes in their lifetime), this translates into 4.7 million newly established smokers in the United States between 1988 and 1998 because of advertising and promotions. An estimated $0.60 \times 3.5$ million $=2.1$ million can be attributed to Joe Camel, an estimated $0.60 \times 2.0$ million $=1.2$ million to Marlboro, and an estimated $0.60 \times 2.5$ million $=1.5$ million to other brands.

With $50 \%$ of ever-smokers likely to still be smoking at age 35 , and $50 \%$ of those who smoke that long dying of smoking-attributable diseases, we estimate that the Joe Camel campaign will account for around 520000 future smoking-attributable deaths, that the Marlboro campaign will account for around 300000 deaths, and other brands will account for around 380000 deaths, among smokers first experimenting with cigarettes from 1988 to 1998. Overall, we estimate that tobacco advertising and promotions will result in 1.2 
Table 4 Projected numbers of new experimenters attributable to the foe Camel, Marlboro, and other campaigns from the 1993 and 1996 California Tobacco Surveys

\begin{tabular}{lllrl}
\hline & $\begin{array}{l}\text { All advertising/ } \\
\text { promotions }\end{array}$ & Camel campaign & $\begin{array}{l}\text { Marlboro } \\
\text { campaign }\end{array}$ & Other campaigns \\
\hline 1988-1994 & 4644734 & 2005132 & 971678 & 1667924 \\
1995-1998 & 3305148 & 1459884 & 1002782 & 842482 \\
Overall: 1988-1998 & 7949882 & 3465016 & 1974460 & 2510406 \\
\hline
\end{tabular}

million future deaths among adolescents experimenting for the first time during this period.

Using the additional brand information available from the hypothetical 'would buy' question as equivalent to the brand of the favourite advertisement, the Joe Camel advertising and promotional campaign would be responsible for 3.0 million new experimenters over this period and the Marlboro campaign for 2.9 million. This translates to 459000 future smoking-attributable deaths in the United States for the Camel campaign and 437000 for the Marlboro campaign.

\section{Discussion}

In 1993 and 1996, over two-thirds of confirmed never-smokers in California were receptive to tobacco advertising and promotional practices. Two brands, Camel and Marlboro, dominated the named favourite advertisements, accounting for over $70 \%$ of the brands named by receptive, confirmed never-smokers in each year. RJ Reynold's Joe Camel advertising was named by about half of adolescents receptive to tobacco advertising each year, with Marboro a distant second at about $20 \%$. As has been previously noted, ${ }^{32}$ these same two brands have dominated the promotional items market as well. However, there was a marked shift in the ownership of items from Camel to Marlboro between 1993 and 1996. In 1993, Camel brand promotional items were owned by more adolescents than Marlboro's, but in $1996,50 \%$ of the promotional items owned by receptive, adolescent, confirmed never-smokers were for Marlboro, compared with only about $20 \%$ for Camel.

It is interesting that Phillip Morris, the manufacturer of Marlboro cigarettes, did not rush to meet the threat of the popular Joe Camel advertising campaign to their long standing dominance $e^{4-7}$ of the adolescent market with a new advertising campaign of its own. However, an innovative part of the Joe Camel campaign was the Camel Cash promotional programme introduced by RJ Reynolds in 1991. The Marlboro response to the Camel threat came when Phillip Morris introduced the Marlboro Adventure Team promotional catalogue. Thus, the competition between the brands for the youth market occurred via promotions rather than advertising. By 1996, ownership of Marlboro brand promotional items was far more prevalent than Camel's. Industry-wide, the percentage of the advertising and promotional budget devoted to promotional items has increased substantially in recent years. ${ }^{28}$

For adolescents who smoke, brand choice depends to a large extent on the brands that their friends smoke. ${ }^{33}$ Adolescent experimenters get most of their cigarettes from others, so there is probably little brand loyalty during this period. Whether the rate of conversion to established smoking is influenced by the brand smoked most often during the experimentation period is unknown; we assumed that it is not. Not until adolescents consume so many cigarettes that they can no longer rely on the generosity of their friends do they typically buy their own. ${ }^{33}$ Adolescents state that their friends' brand is an important consideration for them when they begin to buy their own cigarettes. ${ }^{33}$ Because most adolescent cigarette buyers buy Marlboros, ${ }^{67}$ they are more likely to obtain Marlboro promotional items, either at the point-of-sale or through coupon redemption. Since adolescents often are given promotional items by others, ${ }^{32}$ it was not surprising that the Marlboro promotional campaign quickly dominated the promotional item "market share," even among confirmed never-smokers.

Established smokers may switch brands, and whether or not some brands or types of cigarette within a brand are more lethal than others has not been established. ${ }^{2}$ There is no substantial evidence that long-term smokers of high nicotine (and thus high tar and carbon monoxide) cigarettes are more likely to have health consequences than smokers of the so called "light" brands. The controlled laboratory data that measure nicotine and tar content appear to bear little relation to what a smoker actually derives from a cigarette. Smokers titrate their nicotine dose by taking more puffs, inhaling deeper, covering the holes that allow filters to work, and in some cases by smoking more cigarettes. ${ }^{35}{ }^{36}$ Rather than blame smoking-attributable mortality on the brand(s) smokers smoke after becoming established smokers, we assign responsibility according to the influence on first experimentation. Without that first step, established smoking would not happen.

We maintain that while tobacco advertising or promotional campaigns may bolster cigarette sales among young cigarette smokers who buy cigarettes, ${ }^{47}$ they also create interest in smoking among confirmed never-smokers that increases the likelihood of future smoking. ${ }^{11}{ }^{12}$ Thus, to the extent that a campaign captures the attention of these never-smokers, we blame it for adolescent smoking uptake. For this reason, we reapportioned the number of new experimenters because of promotional item brand "market share" for 1995 and later to account for Marlboro's new dominance. The increased "market share" of Marlboro promotional items led to our holding this brand responsible for a substantial number of new experimenters from 1995 to 1998.

Although there may be other ways to apportion the blame, no other has been published. Our method takes into account the relative importance to future experimentation of advertising and promotions and the relative prevalence of these types of receptivity among confirmed adolescent never-smokers. We used 
population data to estimate the "market share" of favourite advertisements and promotional item ownership for each brand. After estimating the proportion of new experimenters attributable to each brand's advertising and promotional activities, we used conservative numbers for the total numbers of new experimenters, and the proportion who become established smokers to compute estimates for the expected numbers of future smoking-attributable deaths that can be assigned to each brand's advertising and promotional activities. Our estimates suggest that Marlboro will ultimately be responsible for between 300000 and 437000 future deaths in the United States, compared with between 459000 and 520000 future deaths because of the "Joe Camel" campaign among new smokers recruited from 1988 to 1998.

The strategies adopted by RJ Reynolds and Phillip Morris to advertise and promote their cigarette brands appear consistent with the objective to capture a share of the youth marked outlined in the confidential RJ Reynolds research planning memorandum. ${ }^{1}$ The "Joe Camel" campaign certainly caught the attention of children and young people. ${ }^{37-39}$ Furthermore, the subsequent switch in emphasis away from advertising to promotional items suggests that this strategy was identified as a promising tactic for "influencing pre-smokers to try smoking, learn to smoke and become confirmed smokers."1

Support for this work was by funding from the Cancer Prevention Research Unit NIH Grant CA72092, National Cancer Institute, Bethesda, Maryland. Data were collected under ConInstitute, Bethesda, Maryland. Data were collected under Conices, Tobacco Control Section, Sacramento, California. Dr Pierce is supported in part by an Established Investigator Award from the American Heart Association.

\section{Appendix}

If $r(p)$ is the proportion of receptivity accounted for by promotions and $r(a)$ is the proportion accounted for by advertisements, the relative prevalence of promotions and advertising receptivity, $\mathrm{r}(\mathrm{p}) / \mathrm{r}(\mathrm{a})$, is about 0.3 so that $\mathrm{r}(\mathrm{p})=$ $0.3 \times \mathrm{r}(\mathrm{a})$. For the moment, assume that promotions are 1.5 times more important in influencing future smoking than favourite advertisements, or $\mathrm{I}(\mathrm{p}) / \mathrm{I}(\mathrm{a})=1.5$ so that $\mathrm{I}(\mathrm{p})=$ $1.5 \times I(a)$, where $I(p)$ is the importance of promotions and $\mathrm{I}(\mathrm{a})$ is the importance of advertisements. The total effect advertising and promotions effect can be expressed as follows:

$\mathrm{e}(\mathrm{a})+\mathrm{e}(\mathrm{p})=1.0$ or $\mathrm{I}(\mathrm{a}) \times \mathrm{r}(\mathrm{a})+\mathrm{I}(\mathrm{p}) \times \mathrm{r}(\mathrm{p})=1.0$.

Substituting for $r(p)$ in terms of $r(a)$ and $I(p)$ in terms of $\mathrm{I}(\mathrm{a})$ (see above) produces the equation:

$\mathrm{I}(\mathrm{a}) \times \mathrm{r}(\mathrm{a})+[1.5 \times \mathrm{I}(\mathrm{a})] \times[0.3 \times \mathrm{r}(\mathrm{a})]=1.0$.

Solving algebraically for the quantity, $\mathrm{I}(\mathrm{a}) \times \mathrm{r}(\mathrm{a})$, which is really $\mathrm{e}(\mathrm{a})$, yields $\mathrm{e}(\mathrm{a})=0.69$.

The number of new experimenters attributed to each brand for several values of e(a) are indicated below. An e(a) of 0.8 is based on the assumption that promotions are slightly less important than advertisements; 0.7 assumes that they are just over 1.5 times more

\begin{tabular}{cccc}
\hline e(a) & Camel & Marlboro & Other brands \\
\hline 0.8 & 3662470 & 1902516 & 2384897 \\
0.7 & 3465016 & 1974460 & 2510406 \\
0.6 & 3265579 & 2076151 & 2608152 \\
\hline
\end{tabular}

important, and 0.8 assumes that they are over twice as important.

The results presented in table 4 are based on an $\mathrm{e}(\mathrm{a})$ of 0.7 .

1 RJ Reynolds confidential research planning memorandum, 2 February 1973.

2 US Department of Health and Human Services. Reducing the health consequences of smoking: 25 years of progress. A report of the Surgeon General, 1989. Rockville, Maryland: report of the Surgeon General, 1989. Rockville, Maryland: on Smoking and Health, 1989. (DHHS Publication No (CDC) 89-8411.)

3 US Department of Health and Human Services. Preventing tobacco use among young people. A report of the Surgeon General, 1994. Atlanta, Georgia: Public Health Service, Centers for Disease Control and Prevention, Office on Smoking and Health, 1994. (US Government Printing Office Publication No S/N 017-001-00491-0.)

4 Pierce JP, Gilpin E, Burns DM, et al. Does tobacco advertising target young people to start smoking? Evidence from California. $¥ A M A$ 1991;266:3154-8.

5 Pollay RW, Siddarth S, Siegel M, et al. The last straw? Cigarette advertising and realized market shares among youths rette advertising and realized market shares among

6 US Centers for Disease Control. Comparison of the cigarette brand preferences of adult and teenage smokers-United States, 1989, and 10 US communities, 1988 and 1990. MMWR 1992;41:169-81.

7 US Centers for Disease Control and Prevention. Changes in United States, 1989-1993. MMWR 1994;43:577-81.

8 King C, Siegel M, Celebucki C, et al. Adolescent exposure to cigarette advertising in magazines: an evaluation of brand-specific advertising in relation to youth readership. fAMA 1998;279:516-20.

9 Pierce JP, Lee L, Gilpin EA. Smoking initiation by adolescent girls, 1944 through 1988: an association with targeted advertising. ₹AMA 1994;23:608-11.

10 Pierce JP, Gilpin EA. A historical analysis of tobacco marketing and the uptake of smoking by youth in the United States: 1890-1977. Health Psych 1995;14:500-8.

11 Evans N, Farkas A, Gilpin E, et al. Influence of tobacco marketing and exposure to smokers on adolescent susceptibility to smoking. $\mathcal{F}$ Natl Cancer Inst 1995;87:1538-45.

12 Pierce JP, Choi WS, Gilpin EA, et al. Tobacco industry promotion of cigarettes and adolescent smoking. $\mathscr{f} A M A$ 1998:279:511-15.

13 Susser M. Causal thinking in the health sciences: concepts and strategies in epidemiology. New York: Oxford University Press, 1973.

14 McGuire WJ. Attitudes and attitude change. Lindzey G, Anderson E, eds. The handbook of social psychology II, 3rd ed. New York: Random House, 1985

15 Russell MAH. The nicotine addiction trap: a 40-year sentence for four cigarettes. Br F Addict 1990;85:293-300.

16 Choi WS, Pierce JP, Gilpin EA, et al. Which adolescent experimenters progress to established smoking in the United States? Am 尹 Prev Med 1997;13:385-91.

17 US Centers for Disease Control and Prevention. Selected cigarette smoking initiation and quitting behaviors among high school students-United States, 1997. MMWR 1998;47:386-9.

18 Mattson ME, Pollack ES, Cullen JW. What are the odds smoking will kill you? Am f Public Health 1987;77:425-31.

19 Doll R, Peto R, Wheatley, et al. Mortality in relation to smoking: 40 years observation on male British doctors. BMF 1994;309:901-11.

20 Thun MJ, Day-Lally C, Myers DG, et al. Trends in tobacco smoking and mortality from cigarette use in Cancer Prevention Studies I (1959 through 1965) and II (1982 through 1988). In: Changes in cigarette-related disease risks and their implication for prevention and control. Smoking and Tobacco Control Monograph 8. Bethesda, Maryland: National Institutes of Health, National Cancer Institute, 1997.

21 Kessler GE, Daynard RA. Tobacco litigation as a public health and cancer control strategy. F Am Med Wom Assoc 1996;51:57-62.

22 Bal DG, Kizer KW, Felten PG, et al. Reducing tobacco consumption in California. FAMA 1990;264:1570-4.

23 Pierce JP, Cavin SW, Macky C, et al. Technical report on analytic methods and approaches used in the 1993 California Tobacco Survey analysis. Sacramento, California: California Department of Health Services, 1994.

24 Pierce JP, Berry CC, Gilpin EA, et al. Technical report on analytic methods and approaches used in the 1996 California Tobacco Survey analysis. Vols 1 and 2. La Jolla, California: University of California, San Diego, 1998.

25 Pierce JP, Fiore MC, Novotny TE, et al. Trends in cigarette smoking in the United States: projections to the year 2000. fAMA 1989;261:61-5. 
26 Pierce JP, Gilpin EA. How long will today's new adolescent smoker be addicted to cigarettes? Am 7 Public Health 1995;86:253-6.

27 US Centers for Disease Control and Prevention. Incidence of initiation of cigarette smoking - United States, 19651996. MMWR 1998;47:837-40

28 Gilpin EA, Pierce JP. Trends in adolescent smoking initiation in the United States: is tobacco marketing an influence? Tobacco Control 1997;6:122-7.

29 Johnston LD, O'Malley PM, Bachman JG. National survey results on drug use from the Monitoring the Future Study, 1975-1992. Vol 1: Secondary school students. Washington, DC: US Department of Health and Human Services, Public Health Service, National Institutes of Health, National Institute of Drug Abuse, 1994.

30 US Centers for Disease Control and Prevention. Trends in smoking initiation among adolescents and young adultssmoking initiation among adolescents and young ad
United States, 1980-1989. MMWR 1995;44:521-5.

31 Burns D, Pierce JP. Tobacco use in California. Sacramento, California: California Department of Health Services,

32 Gilpin EA, Pierce JP, Rosbrook B. Are adolescents receptive to current sales promotion practices of the tobacco industry? Prev Med 1997:26:14-21.
33 Pierce JP, Gilpin EA, Emery SL, et al. Tobacco control in California; who's winning the war? An evaluation of the Diego, 1998 . University of California, San Diego, 1998.

34 Emery S, Gilpin EA, White MM, et al. How adolescents get their cigarettes: implications for policies on access and price. F Natl Cancer Inst 1999;91:184-6.

35 Zacny JP, Stitzer ML. Cigarette brand-switching: effects on smoke exposure and smoking behavior. F Pharmacol Exp Ther 1988;246:619-27.

36 Kolonen S, Tuomisto J, Puustinen P, et al. Effects of smoking abstinence and chain-smoking on puffing topography and diurnal nicotine exposure. Pharmacol Biochem Behav 1992;42:327-32.

37 Fischer PM, Schwartz MP, Richards JW Jr, et al. Brand logo recognition by children aged 3 to 6 years. Mickey Mouse and Old Joe the Camel. $\mathscr{F} A M A$ 1991;266:3145-8.

38 DiFranza JR, Richards JW, Paulman PM, et al. RJR Nabisco's cartoon camel promotes Camel cigarettes to children. $7 A M A$ 1991;166:3149-53.

39 Mizerski R. The relationship between cartoon trade character recognition and attitude toward produce category in young children. F Marketing 1995;59:58-70.

\section{Tobacco Control <http://www.tobaccocontrol.com>}

Visitors to the world wide web can now access Tobacco Control either through the BMJ Publishing Group's home page <http://www.bmj.com> or directly by using its individual URL < http://www.tobaccocontrol.com>. There they will find the following.

- Current contents list for the journal

- Contents lists of previous issues

- Members of the editorial board

- Subscribers' information

- Instructions for authors

- Details of reprint services.

There is also a longer version of the "Play It Again" section of Tobacco Control that was published in the Winter 1996 issue of the journal, cataloguing tobacco-related quotes made during the 1996 United States presidential campaign.

A hotlink gives access to:

- BMJ Publishing Group home page

- British Medical Association web site

- Online books catalogue

- BMJ Publishing Group books

The web site is at a preliminary stage and there are plans to develop it into a more sophisticated site. Suggestions from visitors about features they would like to see are welcomed. They can be left via the opening page of the BMJ Publishing Group site or, alternatively, via the journal page, through "About this site". 